The consortium consists of the Kennecott Copper Corporation (United States), RTZ and consolidated Gold Fields, Mitsubishi Corporation (Japan) and Noranda Mines Ltd (Canada). Its programme will include work on the nature and location of deposits of manganese nodules under the Pacific Ocean and investigation of methods for working, transporting and extracting useful metals from them. The programme is expected to last five years and to cost more than $\$ 50$ million.

Manganese nodulues occur naturally on the beds of all oceans, generally at depths greater than $1,000 \mathrm{~m}$ : the richest metalbearing nodules have been found in the Pacific at depths of about $5,000 \mathrm{~m}$. The content of the nodules varies greatly but the usual range for deep sea nodules is manganese $(12 \%$ to $34 \%)$, copper $(0.1 \%$ to $1.5 \%)$, cobalt $(0.1 \%$ to $0.3 \%)$ and iron $(1.6 \%$ to $18 \%)$.

\title{
correspondence
}

\section{Embryos and Ethics}

Sir,-According to Dr Anne McLaren's review (Nature, 247: 121) of "The Mammalian Fetus in vitro", Professor R. A. McCance "regrets that the Advisory Group recommended that foetuses of more than 20 weeks' gestation should be considered viable, since he feels that this creates a 'shadowy period of 8 weeks' during which abortions can be performed, yet the use of the abortuses for experiments may become illegal".

But the Infant Life (Preservation) Act 1929 defines destroying any viable fetus as the crime of "Child Destruction', unless done "in good faith for the purpose only of preserving the life of the mother". It continues ". . . evidence that a woman had at any material time been pregnant for a period of 28 weeks or more shall be primâ facie proof that she was at that time pregnant of a child capable of being born alive". But it nowhere says that before 28 weeks the child can be presumed not to be viable, and nowadays a healthy baby of 24 weeks may well live under intensive care.

So if there are any prospects of viability at all a pregnancy may only be terminated to preserve the mother's life, and everything possible must still be done to save the child after delivery. A doctor who fails in this duty, by allowing experimentation or otherwise, would at the very least face a charge of manslaughter by neglect, if at autopsy the baby was found to have been capable of surviving, given proper care.

There have been a few reports of survival from well under 24 weeks, though the real reason for setting a limit at 20 weeks is to allow for mistakes over dates and so on. But, in spite of a wide spread belief to the contrary, the 28th week has no special significance, and anyone experimenting with an abortus at any age near to viability does so at his peril. Viability is a biological fact, not a matter merely of legal definition, and there can be no "shadowy period" during which the child may be presumed inviable by reference simply to dates, either for abortion or for any other purpose.

$$
\begin{aligned}
& \text { Yours faithfully, } \\
& \text { C. B. GoodHaRT }
\end{aligned}
$$

Gonville and Caius College,

Cambridge CB尺 1TA

\section{Adolescents and science}

SIR,-I feel that an important aspect may be missing in the interesting research made by A. Ahlgren and J. H. Walberg (Nature, 245, 187; 1973).

The attitude towards science among adolescents could have changed for the worse because they may have been taught in a way that gives them the impression that science cannot be understood.

Physics has become so abstract that it is very difficult to teach it so that it remains comprehensible for children and yet up to date in its fundamental principles. For instance, it is verv difficult to teach relativity at an clementary level and it is practically impossible to do the same with quantum mechanics. Therefore one either teaches classical mechanics and later says that this is only a first approximation, or tries to begin with relativistic quantum mechanics. The latter is evidenly impossible in the present state of affairs. The former easily gives the child the feeling that he is being cheated or at least that the real thing is utterly beyond comprehension. A really epoch making book on 'Modern Elementary Physics' is badly needed-but who is going to write it?

Chemistry is even worse off, especially in the United States and in countries like Israel where we are copying what they do. It is very often taught in the wrong order. Instead of making it plausible why we think matter is composed of atoms and molecules and why we think they are as large as they are, teachers begin with electrons, nuclei, neutrons without even trying to make their existence plausible. The result is a hopeless mess. Less intelligent children just repeat the story like parrots while the more intelligent ones despair. Then chemistry is built on these shaky foundations with a not much more stable superstructure. England is much better off in this respect than many countries. A professor at the Technical University in Stockholm told me also that the decreasing number of chemistry students is probably due to this way of teaching in high schools.

Biology is often ruined by introducing biochemical concepts not necessary at that level, and which quite certainly cannot even be understood. Presenting the formulae of sugars and amino acids before the elements of chemistry have been taught in the chemistry course is evidently absurd. A very intelligent 17 year old boy in New York told me that he has to write a paper on the chemical foundations of genetics, with nucleic acids and so on involved, without even an elementary knowledge of organic chemistry. The Krebs cycle is also one of the preferred subjects. Any half-way intelligent child feels that he is being bluffed and suspects something wrong in science at large.

We shall have to stop bluffing children and build elementary science courses on solid, understandable foundations if we want intelligent adolescents to turn their preference towards science again.

Yours faithfully,

\section{F. DE KöRÖsY}

Negev Institute for Arid Zone

Research, P.O.B. 1025,

Beer Sheva 